\title{
High Frequency of Osteopenia and Osteoporosis in Alcoholic Chronic Pancreatitis Patients: Preliminary Results
}

Sobral MB, Pereira RM, Faintuch J, Marzinotto MAN, Teixeira AC, Carrilho FJ and Oliveira CP*

University of São Paulo School of Medicine, Brazil

*Corresponding author: Oliveira CP, University of Sao Paulo School of Medicine, Gastroenterology, Brazil, Tel: + 551130617301 , E-mail: cpm@usp.br

Rec Date: Feb 14, 2014, Acc Date: Mar 26, 2014, Pub Date: April 28, 2014

Copyright: () 2014 Sobral MB, et al. This is an open-access article distributed under the terms of the Creative Commons Attribution License, which permits unrestricted use, distribution, and reproduction in any medium, provided the original author and source are credited.

\begin{abstract}
Background: Bone mineral loss is a public health problem in the aged. However information about non elderly males with chronic alcoholic pancreatitis is scarce. Aiming to examine the correlates of Bone Mineral Density (BMD) in this population, a prospective study was conducted.

Methods: Clinically stable, abstinent patients $(\mathrm{N}=25)$ were stratified according to $B M D$ is osteopenia, osteoporosis and Normal groups. Methods included clinical history, dietary recall, biochemical and hormonal profile, and body composition estimated by whole body and segmental bioimpedance analysis, along with bone mineral density (DXA).

Results: Patients had a history of alcohol abuse of around 2-3 decades. Despite remaining alcohol-free for a mean of $6-12$ years depending on the group, more than one third were already diabetic. Nutritional status was acceptable and biochemical tests essentially normal. Main differences in osteoporosis concerned higher age $(p=0.038)$, lower lipid intake $(p=0.031)$. In the other side, body weight, lean body mass and fat mass numerically diminished, however without statistical difference.

Conclusions: Abnormal bone mineral density affected more than $80 \%$ of this male population, despite stable disease, alcohol abstinence and lack of protein-calorie malnutrition. Older age was relevant, and reduced body mass might play a role as well. Findings are consistent with a substantial risk for osteopenia/ osteoporosis, much higher than previously reported. Additional studies are required to establish dietary, pharmacological and lifestyle guidelines for this population.
\end{abstract}

Keywords: Alcoholic pancreatitis; Chronic pancreatitis; Protein calorie malnutrition; Osteoporosis; Osteopenia; Body composition; Bone mineral density; Bioimpedance analysis

\section{Introduction}

Bones are composed of active metabolic tissue with several functions for the body, including support, mechanical protection of vital organs, Production of blood cells and storage of mineral. Therefore, undergoes a continuous process of renovation and remodeling. Many conditions, such as age, bone metabolic diseases, reduced mobility, drug action, among others, may change the balance between formation and resorption, leading to the predominance of one over the other [1].

Male osteoporosis, according to the National Health and Nutrition Examination Survey III, affects about 3-6\% of American men, despite this, only a small proportion of male patients with fractures receive any specific treatment for osteoporosis [2].

Patients with gastrointestinal diseases, osteoporosis is also prevalent, and the reasons for this are diverse. The American Gastroenterological Association has published two guides of conduct with specific recommendations for screening and treatment of bone metabolic diseases in these groups. However, chronic pancreatitis was not mentioned in these guides $[3,4]$.
Bone metabolic diseases are multifactorial and should be emphasized that the population of chronic pancreatitis exposed to other risk factors for bone loss, such as malnutrition, low levels of muscle mass and consuming large quantities of alcohol and cigarettes. In our environment the main cause for chronic pancreatitis is alcohol, and patients are mostly male. In another study has been shown that these patients are malnourished [5].

The aim of this study is to evaluate the prevalence of osteoporosis and nutritional characteristics of this group.

\section{Methods}

\section{Patients}

This is a cross-sectional study of patients selected from the population attended in the Pancreas Outpatient Gastroenterology Department, School Medicine of University of São Paulo. The inclusion criteria were: male (25-65 years) patients with chronic alcoholic pancreatitis and absence of active alcoholism. All patients included in this study had been without use of alcohol more than sixty months. The exclusion criteria was: female, under 25 or over 65 years old, patients with chronic pancreatitis of other etiologies, patients with cirrhosis and chronic kidney disease of any etiology, gastrectomy, patients with celiac disease, inflammatory bowel disease, medications that may interfere in bone metabolism (systemic glucocorticoids, 
anticonvulsants, heparin, ketoconazole, diuretics), hypogonadism and refusal to participate in the protocol. All patients gave written informed consent, and this protocol was approved by the institutional Ethical Committee of School Medicine of University of São Paulo.

\section{Laboratory assays}

Complete blood count, platelet, liver and pancreatic enzymes, calcium, ionic calcium, phosphorus, glucose, protein, creatinine, urea, alkaline phosphatase, intact parathormone, 25-hydroxy vitamin $\mathrm{D}$, thyroid-stimulating hormone, free T4 and, 24 hour urinary calcium.

\section{Dual-energy X-Ray absorptiometry}

All patients underwent bone density by dual energy X-ray absorptiometry (DXA) for measurement of bone mineral density using a Hologic QDR 4500A densitometry equipment (Hologic Inc. Bedford, MA, USA, Discovery model). Bone mineral density was determined at the following sites: lumbar spine, femoral neck, total hip, and whole body. In this exam, bone mass is reported as an absolute value in $\mathrm{g} /$ $\mathrm{cm} 2$, T-score (compared to the average bone mass of a young healthy individual adult) and Z-score (paired comparison to age and sex of a standard reference).Osteoporosis: T-score $<2.5 \mathrm{SD}$, Osteopenia: Tscore between -1.0 to $-2.5 \mathrm{SD}$, Normal: T-score $\geq=-1.0 \mathrm{SD}$.

All of the measurements were carried out by the same trained technician. The precision errors for bone mineral density measurements were determined based on the standard protocols from The International Society for Clinical Densitometry (ISCD) [6].The least significant change is considered to be $0.033 \mathrm{~g} / \mathrm{cm}^{2}, 0.047 \mathrm{~g} / \mathrm{cm}^{2}$, $0.039 \mathrm{~g} / \mathrm{cm}^{2}$, and $0.010 \mathrm{~g} / \mathrm{cm}^{2}$ for the lumbar spine, the femoral neck, the total hip, and the whole body, respectively [7].

\section{Dietary intake}

Dietary recall (3 days) was conducted by dietitian. The patient was asked to collect information from two days a week and one in the weekend. Foods and drinks, including snacks and visits to bars and restaurants, were classified on the basis of ingredients, home and commercial portion sizes as well as cooking methods, and industrialized items according to composition. Results were processed by Avanutri software (Rio de Janeiro, Brazil, 2004).

\section{Anthropometrics parameters and body composition}

Anthropometrics variables [weight, height, Body Mass Index (BMI), Waist Circumference (WC)] and body composition parameters [whole-body [Intracellular water (ICW), extracellular water (ECW), Body Fat Mass (BFM), Percent body fat (PBF)] and segmental [Lean balance trunk (LBT), lean balance right leg (LBRL), lean balance left leg (LBLL)] were measure by bio impedance analysis (Biospace model InBody $720^{\circ}$ Gangnamgu, Seoul, Korea).

Also lean mass and fat mass was determined by DXA using a Hologic QDR 4500A densitometry equipment (Hologic Inc. Bedford, MA, USA, Discovery model).

\section{Statistical analysis}

The results were presented as mean \pm SE (standard error). To compare the values of normal distribution we used analysis of variance (ANOVA), and nonparametric were examined by Kruskal-Wallis method (Fields, 1984). Standard error was used instead of the standard deviation due to the number of patients in each group.

\section{Results}

\section{Demographic and clinical characteristics}

Twenty-five patients were included in this study according inclusion criteria and all patients had alcoholic chronic pancreatitis. According to the bone mineral density by DXA, patients were classified as osteopenia (68\%), osteoporosis (16\%) and normal (16\%).

Table 1 shows the demographic and clinical characteristics of patients with chronic alcoholic pancreatitis according bone mineral density classification (normal, osteopenia and osteoporosis). The age of the patients with osteopenia and osteoporosis were similar, however, the age of the patients that do not have any disorder of bone mineral density was lower compared to the other groups $(p=0.038)$. There are no statistical differences between these three groups considering BMI, daily alcohol consumption $(\mathrm{mL})$, time of abstinence, the presence of diabetes, surgery or abdominal pain.

\begin{tabular}{|c|c|c|c|c|}
\hline & Normal & Osteopenia & $\begin{array}{l}\text { Osteopor } \\
\text { osis }\end{array}$ & $\begin{array}{l}\text { P- } \\
\text { value }\end{array}$ \\
\hline Age (years) & $46 \pm 2.71$ & $55.18 \pm 1.44$ & $\begin{array}{ll}55.5 & \pm \\
3.86 & \end{array}$ & 0.038 \\
\hline BMI (kg/m2) & $24.75 \pm 1.87$ & $22.84 \pm 0.69$ & $\begin{array}{ll}20.66 & \pm \\
0.47 & \end{array}$ & 0.147 \\
\hline Waist-hip ratio $(\mathrm{cm} / \mathrm{cm})$ & $0.89 \pm 0.05$ & $0.94 \pm 0.02$ & $\begin{array}{ll}0.92 & \pm \\
0.02 & \end{array}$ & 0.428 \\
\hline $\begin{array}{l}\text { Daily alcohol } \\
\text { consumption }(\mathrm{mL})\end{array}$ & $\begin{array}{ll}1175 & \pm \\
630.31 & \end{array}$ & $\begin{array}{ll}885.29 & \pm \\
123.87 & \end{array}$ & $\begin{array}{ll}1125 & \pm \\
125\end{array}$ & 0.503 \\
\hline $\begin{array}{l}\text { Alcohol consumption } \\
\text { (years) }\end{array}$ & $20.5 \pm 5.72$ & $24.41 \pm 1.82$ & $28 \pm 5.43$ & 0.483 \\
\hline $\begin{array}{l}\text { Abstinence from alcohol } \\
\text { (years) }\end{array}$ & $8 \pm 1,08$ & $11.68 \pm 1.48$ & $\begin{array}{ll}5.56 & \pm \\
2.17 & \end{array}$ & 0.118 \\
\hline Diabetes & $25 \%$ & $41.18 \%$ & $50 \%$ & 1 \\
\hline Abdominal pain & $25 \%$ & $35.29 \%$ & $25 \%$ & 1 \\
\hline Surgery & $25 \%$ & $41.18 \%$ & $75 \%$ & 0.494 \\
\hline
\end{tabular}

Table 1: Demographic and clinical characteristics of patients with chronic alcoholic pancreatitis according bone mineral density classification

In Tables 2 and 3 are listed calories, macro and micronutrients obtained in the three day dietary recall values. The amount of lipids ingested in group with osteoporosis was lower than compared to the others groups (normal and osteopenia) ( $\mathrm{p}=0.031)$.Of all the micronutrients vitamin B1 was the only one that had a statistically significant in Osteoporosis group $(\mathrm{p}=0.001)$.

In Table 4 , the average body composition by bioelectrical impedance obtained in the three groups can be observed, with no differences among them. 
Citation: Sobral MB, Pereira RM, Faintuch J, Marzinotto MAN, Teixeira AC, et al. (2014) High Frequency of Osteopenia and Osteoporosis in Alcoholic Chronic Pancreatitis Patients: Preliminary Results. J Nutr Disorders Ther 4: 139. doi:10.4172/2161-0509.1000139

Page 3 of 5

Table 5 presents the data found in lean mass and fat mass obtain by DXA. Patients with osteoporosis had lower level of lean mass and fat mass compared to the other groups, but no statistical difference.

Table 6 shows the results of laboratory tests. Patients in three groups showed normal tests, only glucose was higher in the groups with osteoporosis and osteopenia because most of these patients were diabetics.

\section{Discussion}

In the present study, $84 \%$ of the male patients with alcoholic chronic pancreatitis had bone mineral density compromise and the found major factors that were associated with osteopenia or osteoporosis were age and consumption of lipids, risk factors that could suggest a worse progression of the disease. However, the presence of diabetes, the quantity of alcohol consumption in years, the $\mathrm{BMI}$ and the fat mass and distribution did not show any effect in this study when compared with patients classified as normal by DXA.

\begin{tabular}{|l|l|l|l|l|}
\hline & Normal & Osteopenia & Osteoporosis & P-value \\
\hline $\begin{array}{l}\text { Calories } \\
\text { (Kcal) }\end{array}$ & $1746.38 \pm 86.09$ & $1707.01 \pm 86.86$ & $\begin{array}{l}1823.63 \\
271.62\end{array}$ & 0.85 \\
\hline $\begin{array}{l}\text { Carbohydra } \\
\text { te }(\mathrm{g})\end{array}$ & $243.95 \pm 17.47$ & $237.72 \pm 14.53$ & $267.04 \pm 27.84$ & 0.653 \\
\hline Proteins (g) & $73.33 \pm 1.45$ & $72.15 \pm 4.36$ & $82.8 \pm 12.94$ & 0.473 \\
\hline Lipids (g) & $53.03 \pm 2.33$ & $51.95 \pm 3.58$ & $47.14 \pm 13.97$ & 0.031 \\
\hline \multicolumn{5}{|l|}{ Data are expressed in mean \pm SD or percentage } \\
\hline
\end{tabular}

Table 2: Macronutrients obtained in the three day dietary recall values in patients with chronic alcoholic pancreatitis according bone mineral density classification. Data are expressed in mean \pm SD or percentage

\begin{tabular}{|c|c|c|c|c|}
\hline & Control & Osteopenia & Osteoporosis & P-value \\
\hline Vitamin $\mathrm{A}(600 \mathrm{RE})$ & $71.58 \pm 35.79$ & $334.78 \pm 81.2$ & $240.93 \pm 120.47$ & 0.244 \\
\hline Vitamin D(5 mcg) & $2.5 \pm 0.67$ & $3.8 \pm 0.7$ & $2.77 \pm 1.24$ & 0.377 \\
\hline Vitamin B1(1,2 mg) & $1.51 \pm 0.13$ & $1.42 \pm 0.12$ & $2.75 \pm 0.45$ & 0.001 \\
\hline Vitamin B2(1,3 mg) & $1.22 \pm 0.08$ & $1.7 \pm 0.24$ & $2.01 \pm 0.42$ & 0.479 \\
\hline Vitamin B3(16 mg) & $16.96 \pm 2.51$ & $18.44 \pm 1.7$ & $20.08 \pm 4.83$ & 0.829 \\
\hline Vitamin B5(5 mg) & $2.69 \pm 0.32$ & $3.74 \pm 0.45$ & $3.65 \pm 0.52$ & 0.394 \\
\hline Vitamin B6(1.3 mg) & $0.8 \pm 0.08$ & $1.19 \pm 0.13$ & $1.41 \pm 0.23$ & 0.228 \\
\hline Vitamin B12(2.4 mcg) & $2.17 \pm 0.25$ & $10.5 \pm 4.83$ & $2.43 \pm 0.94$ & 0.558 \\
\hline Vitamin C(45 mg) & $82.07 \pm 31.11$ & $133.13 \pm 77.38$ & $185.06 \pm 56.29$ & 0.215 \\
\hline Vitamin $E(10 \mathrm{mg})$ & $8.94 \pm 2.4$ & $9.79 \pm 1.16$ & $7.74 \pm 1.92$ & 0.726 \\
\hline Folic acid (400 mcg) & $126.08 \pm 9.2$ & $124.39 \pm 16.08$ & $134.57 \pm 28.87$ & 0.956 \\
\hline Calcium (1000 mg) & $501.28 \pm 92.81$ & $643.68 \pm 96.95$ & $604.13 \pm 144.2$ & 0.8 \\
\hline Phosphorus (700 mg) & $947.61 \pm 56.5$ & $995.81 \pm 76.1$ & $892.78 \pm 177.61$ & 0.816 \\
\hline Magnesium (260 mg) & $199.3 \pm 13.73$ & $226.02 \pm 17.1$ & $204.76 \pm 25.59$ & 0.681 \\
\hline Iron (14 mg) & $12.94 \pm 1.3$ & $25.91 \pm 8.28$ & $12 \pm 1.41$ & 0.579 \\
\hline Zinc (7 mg) & $8.94 \pm 1.16$ & $9.55 \pm 0.7$ & $9.79 \pm 0.87$ & 0.893 \\
\hline Copper (2 mg) & $1.07 \pm 0.1$ & $1.58 \pm 0.23$ & $1.05 \pm 0.1$ & 0.317 \\
\hline lodine (130 mcg) & $35.56 \pm 15.18$ & $65.31 \pm 12.6$ & $55.98 \pm 22.4$ & 0.495 \\
\hline Selenium (34 mcg) & $62.86 \pm 11.69$ & $73.16 \pm 8.11$ & $69.12 \pm 21.28$ & 0.855 \\
\hline Manganese (2,3 mg) & $1.68 \pm 0.24$ & $2.18 \pm 0.32$ & $1.57 \pm 0.12$ & 0.439 \\
\hline Potassium(4700 mg) & $1883.92 \pm 112.7$ & $2057.05 \pm 116.19$ & $2198.77 \pm 288.16$ & 0.778 \\
\hline Sodium (2000 mg) & $1882.5 \pm 285.94$ & $2200.48 \pm 146.1$ & $1805.18 \pm 173.52$ & 0.356 \\
\hline
\end{tabular}


Citation: Sobral MB, Pereira RM, Faintuch J, Marzinotto MAN, Teixeira AC, et al. (2014) High Frequency of Osteopenia and Osteoporosis in Alcoholic Chronic Pancreatitis Patients: Preliminary Results. J Nutr Disorders Ther 4: 139. doi:10.4172/2161-0509.1000139

Page 4 of 5

Data are expressed in mean \pm SD or percentage

Table 3: Micronutrients obtained in the three day dietary recall values in patients with chronic alcoholic pancreatitis according bone mineral density classification

\begin{tabular}{|l|l|l|l|l|}
\hline & Normal & Osteopenia & Osteoporosis & P-value \\
\hline Weight $(\mathrm{kg})$ & $\begin{array}{l}73.92 \\
5.07\end{array}$ & $69.56 \pm 2.14$ & $63.08 \pm 1.73$ & 0.211 \\
\hline Height $(\mathrm{m})$ & $\begin{array}{l}1.73 \\
0.01\end{array}$ & $\pm 1.75 \pm 0.02$ & $1.75 \pm 0.03$ & 0.886 \\
\hline Lean mass $(\mathrm{kg})$ & $\begin{array}{l}31.32 \quad \pm \\
2.12\end{array}$ & $29.28 \pm 0.86$ & $28.85 \pm 2.2$ & 0.581 \\
\hline Fat mass (\%) & 23.95 & 23.08 & 17.57 & 0.426 \\
\hline $\begin{array}{l}\text { Intracellular water } \\
(\mathrm{L})\end{array}$ & $\begin{array}{l}25.6 \quad \pm \\
1.62\end{array}$ & $23.99 \pm 0.66$ & $23.65 \pm 1.69$ & 0.564 \\
\hline $\begin{array}{l}\text { Extracellular } \\
\text { water (L) }\end{array}$ & $\begin{array}{l}15.6 \\
0.83\end{array}$ & $15.26 \pm 0.43$ & $14.6 \pm 1.1$ & 0.725 \\
\hline
\end{tabular}

Table 4: The average body composition by bioelectrical impedance obtained in patients with chronic alcoholic pancreatitis according bone mineral density classification

\begin{tabular}{|l|l|l|l|l|}
\hline & Normal & Osteopenia & Osteoporosis & P-value \\
\hline Lean mass $(\mathrm{kg})$ & $\begin{array}{l}56.17 \\
3.66\end{array}$ & $52.07 \pm 1.21$ & $48.98 \pm 2.41$ & 0.183 \\
\hline Fat mass (\%) & $\begin{array}{l}20.23 \quad \pm \\
3.06\end{array}$ & $19.75 \pm 1.6$ & $17.35 \pm 2.62$ & 0.769 \\
\hline
\end{tabular}

Table 5:Parameters of lean mass and fat mass by DXA in patients with chronic alcoholic pancreatitis according bone mineral density classification.

\begin{tabular}{|l|l|l|l|l|}
\hline & Normal & Osteopenia & $\begin{array}{l}\text { Osteoporosi } \\
\mathbf{s}\end{array}$ & P-value \\
\hline $\begin{array}{l}\text { Alanine } \\
\text { aminotransferase (U/L) }\end{array}$ & $15 \pm 2.61$ & $23.53 \pm 4.14$ & $11 \pm 1.22$ & 0.077 \\
\hline Amylase (U/L) & $52 \pm 6.04$ & $\begin{array}{l}77.24 \\
11.42\end{array}$ & $78 \pm 14.53$ & 0.547 \\
\hline $\begin{array}{l}\text { Aspartate } \\
\text { aminotransferase (U/L) }\end{array}$ & $18 \pm 1$ & $23.06 \pm 2.45$ & $18.25 \pm 3.12$ & 0.451 \\
\hline Hemoglobin (g/dL) & $15.35 \pm 0.76$ & $14.36 \pm 0.3$ & $13.6 \pm 0.38$ & 0.157 \\
\hline Hematocrit (\%) & $44.3 \pm 2.53$ & $42.74 \pm 0.79$ & $40.08 \pm 0.97$ & 0.228 \\
\hline Leucocyte (mil/mm3) & $6.54 \pm 0.93$ & $8.22 \pm 1.1$ & $8.27 \pm 1.79$ & 0.695 \\
\hline $\begin{array}{l}\text { Erythrocyte } \\
\text { (milhões/mm) }\end{array}$ & $5.1 \pm 0.34$ & $4.81 \pm 0.1$ & $4.48 \pm 0.19$ & 0.158 \\
\hline Platelet (mil/mm $\left.{ }^{3}\right)$ & 204.5 & $\begin{array}{l}226.94 \\
19.2\end{array}$ & $\begin{array}{l}243.75 \\
46.57\end{array}$ & 0.787 \\
\hline
\end{tabular}

\begin{tabular}{|c|c|c|c|c|}
\hline Ionic calcium (mg/dL) & $4.96 \pm 0.23$ & $4.97 \pm 0.08$ & $4.9 \pm 0.13$ & 0.932 \\
\hline $\begin{array}{l}24 \mathrm{~h} \text { urinary calcium } \\
(\mathrm{g} / \mathrm{vol})\end{array}$ & $\begin{array}{ll}94.05 & \pm \\
41.55 & \end{array}$ & $56.46 \pm 9.78$ & $54.4 \pm 32.67$ & 0.434 \\
\hline Calcium (mg/dL) & $9.55 \pm 0.24$ & $9.15 \pm 0.1$ & $9 \pm 0.11$ & 0.139 \\
\hline Phosphorus (mg/dL) & $3.27 \pm 0.18$ & $3.55 \pm 0.17$ & $3.4 \pm 0.2$ & 0.714 \\
\hline Glucose(mg/dL) & $85.75 \pm 5.14$ & $\begin{array}{l}135.76 \quad \pm \\
25.17\end{array}$ & $\begin{array}{ll}161.25 & \pm \\
63.81 & \end{array}$ & 0.387 \\
\hline Protein (g/dL) & $7.35 \pm 0.29$ & $7.35 \pm 0.08$ & $7.3 \pm 0.2$ & 0.976 \\
\hline Albumin (g/dL) & $4.9 \pm 0.18$ & $4.53 \pm 0.1$ & $4.5 \pm 0.24$ & 0.232 \\
\hline Creatinine (mg/dL) & $1.05 \pm 0.06$ & $1.12 \pm 0.1$ & $0.98 \pm 0.25$ & 0.38 \\
\hline Urea (mg/dL) & $34.5 \pm 2.33$ & $38 \pm 4.38$ & $39.75 \pm 7.11$ & 0.818 \\
\hline Parathormone $(\mathrm{pg} / \mathrm{mL})$ & $44.25 \pm 8.24$ & $59.24 \pm 7$ & $55.11 \pm 11.47$ & 0.628 \\
\hline $\begin{array}{l}\text { 25-hydroxy vitamin D } \\
\text { (ng/mL) }\end{array}$ & $29 \pm 4.71$ & $24.58 \pm 2.85$ & $25.25 \pm 5.66$ & 0.75 \\
\hline TSH $(\mu \mathrm{IU} / \mathrm{mL})$ & $3.58 \pm 0.85$ & $2.85 \pm 0.39$ & $1.79 \pm 0.39$ & 0.354 \\
\hline Free t4 (ng/dL) & $1.19 \pm 0.07$ & $1.35 \pm 0.05$ & $1.29 \pm 0.12$ & 0.344 \\
\hline $\begin{array}{l}\text { Alkaline phosphatase } \\
(\mathrm{U} / \mathrm{L})\end{array}$ & $57 \pm 8.46$ & $80.82 \pm 5.77$ & $78.75 \pm 10.87$ & 0.189 \\
\hline
\end{tabular}

Table 6: Laboratory values in patients with chronic alcoholic pancreatitis according bone mineral density classification

However, the major of studies about osteoporosis have long focused on pre- or post-menopausal women, and its presence in men has been underestimated [8]. A new Chinese study investigated the differential impact of fat on BMD (bone mineral density) in bone mineral disorder and examined the relationship with BMD according to Body Mass Index (BMI) levels in Chinese men [8]. In the present study, we included only male and no difference was found between patients with or without bone mineral density compromise in alcoholic chronic pancreatitis according BMI. Moreover the patients with Normal classification by DXA were younger than the patients with osteopenia and osteoporosis.

Lean mass and fat mass in patients with osteopenia and osteoporosis was lower than in Normal group. A Denmark study concluded that patients with chronic pancreatitis, in particular patients with advanced disease and steatorrhea, are at risk to developing significant bone loss. Despite normal body mass index the patients are characterized by loss of lean body mass and fat mass. Besides, this Denmark group showed that these patients have decreased serum levels of vitamin D metabolites and low bone mass [9].

Recently, Mikosch et al. reviewed the different mechanisms and effects of alcohol intake on bone mass, bone metabolism, and bone 
Citation: Sobral MB, Pereira RM, Faintuch J, Marzinotto MAN, Teixeira AC, et al. (2014) High Frequency of Osteopenia and Osteoporosis in Alcoholic Chronic Pancreatitis Patients: Preliminary Results. J Nutr Disorders Ther 4: 139. doi:10.4172/2161-0509.1000139

Page 5 of 5

strength, including alcoholism-related "life-style factors" such as malnutrition, lack of exercise, and hormonal changes as additional causative factors, which also contribute to the development of osteoporosis due to alcohol abuse [10]. Normally, men have lower alcohol abstinence rate than women $(35 \%$ for men and $59 \%$ of women) [10]. This fact could explain that the quantity of alcohol consumption in years did not demonstrated difference between the groups in the present study.

There was no difference between the calories, protein and carbohydrate intake, but lipid was lower in osteoporosis group. Study from The Netherlands argues that in chronic pancreatitis, malabsorption of fat is common due to loss of exocrine function. Consequently, these patients are at risk to acquire deficiencies of the fat-soluble vitamins, which may result in a decreased bone mineral density and the development of osteopenia and osteoporosis [11]. In our study the consumption of lipids was lower osteopenia and osteoporosis groups.

Osteoporosis has been described in chronic pancreatitis, with 21\% of chronic pancreatitis patients having this diagnosis in the earliest study published in 1997. Since then, a number of studies have shown a varied prevalence of osteoporosis from $5 \%$ to $39 \%$.From these studies and others, it is reasonable to assume that patients with chronic pancreatitis may be at risk for osteoporosis and Osteopenia [12]. Recently, an India study concluded that pancreatic osteodystrophy is a novel entity consisting of osteopenia, osteoporosis, and osteomalacia in patients with chronic pancreatitis [13].

Based on recent meta-analysis, almost 1 of 4 patients with chronic pancreatitis has osteoporosis, and almost two-thirds of patients have either osteoporosis or osteopenia. Osteoporosis and osteopenia are underappreciated sources of morbidity in patients with chronic pancreatitis. Bone health management guidelines are urgently required in patients with chronic pancreatitis [12].

In micronutrients the vitamin B1 was more consumed in group osteoporosis. The food group source of $\mathrm{B} 1$ is greens and vegetables, whole cereals and beans. Reviewing the three groups all performed healthy diet.

Dual-energy $\mathrm{x}$-ray absorptiometry remains the diagnostic procedure of choice. Biochemical markers of bone reabsorption have a role in identifying those patients with ongoing bone loss and monitoring their response to therapy. Identification of patients at risk and initiation of measures to prevent bone loss from the optimal therapeutic strategy [14].

\section{Preliminary Conclusions}

The frequency of osteopenia and osteoporosis by DXA in male, patients with chronic pancreatitis of alcoholic etiology was $68 \%$ and $16 \%$, respectively.
Based on the dietary habits, our study observed that the amount of lipids ingested was lower in osteoporosis patients compared to the other groups.

The weight of patients as well as lean mass, was not statistical significant different, probably due to the small number of patients, but it can be observed that the patients who had osteoporosis were thinner compared with the other groups.

\section{References}

1. Vieira JGH (2007) Diagnóstico laboratorial e monitoramento das doenças osteometabólicas.. J Bras Patol Med Lab 43:75-82

2. Looker AC, Orwoll ES, Johnston CC Jr, Lindsay RL, Wahner HW, et al. (1997) Prevalence of low femoral bone density in older U.S. adults from NHANES III. J Bone Miner Res 12: 1761-1768.

3. http://www.worldgastroenterology.org/assets/downloads/en/pdf/ guidelines/17_osteoporosis_en.pdf

4. Guarita DR, Felga GEG, Mott CB (2011)Pancreatitecrônica. In: Zaterka S, Eisig JN (Eds.), Tratado de Gastroenterologia: da graduação à pósgraduação. Editora Atheneu.

5. Guarita DR, Felga GEG, Pedroso MRA, Mott CB (2009) Doenças Pancreáticas. In: Martins MA, Carrilho FJ, Alves VAF, Castilho EA, Cerri GG, (Eds.), Clínica Médica. São Paulo, Editora Manole.

6. Baim S, Wilson CR, Lewiecki EM, Luckey MM, Downs RW Jr, et al. (2005) Precision assessment and radiation safety for dual-energy X-ray absorptiometry: position paper of the International Society for Clinical Densitometry. J Clin Densitom 8: 371-378.

7. Lopes JB, Danilevicius CF, Takayama L, Caparbo VF, Menezes PR, et al. (2011) Prevalence and risk factors of radiographic vertebral fracture in Brazilian community-dwelling elderly. Osteoporos Int 22: 711-719.

8. Kang D, Liu Z, Wang Y, Zhang H, Feng X, et al. (2014) Relationship of body composition with bone mineral density in northern Chinese men by body mass index levels. J Endocrinol Invest.

9. Haaber AB, Rosenfalck AM, Hansen B, Hilsted J, Larsen S (2000) Bone mineral metabolism, bone mineral density, and body composition in patients with chronic pancreatitis and pancreatic exocrine insufficiency. Int J Pancreatol 27: 21-27.

10. Mikosch P (2014) Alcohol and bone. Wien Med Wochenschr.

11. Sikkens EC, Cahen DL, Koch AD, Braat H, Poley JW, et al. (2013) The prevalence of fat-soluble vitamin deficiencies and a decreased bone mass in patients with chronic pancreatitis. Pancreatology 13: 238-242.

12. Duggan SN, Smyth ND, Murphy A, Macnaughton D, O'Keefe SJ, et al. (2014) High prevalence of osteoporosis in patients with chronic pancreatitis: a systematic review and meta-analysis. Clin Gastroenterol Hepatol 12: 219-228.

13. Sudeep K, Chacko A, Thomas N, Selvakumar R, George B, et al. (2011) Predictors of osteodystrophy in patients with chronic nonalcoholic pancreatitis with or without diabetes. Endocr Pract 17: 897-905.

14. Southerland JC, Valentine JF (2001) Osteopenia and osteoporosis in gastrointestinal diseases: diagnosis and treatment. Curr Gastroenterol Rep 3: 399-407. 